\title{
Autochthonous Plasmodium vivax malaria in Greece, 2011
}

K Danis (daniscostas@yahoo.com) ${ }^{1}$, A Baka ${ }^{1}$, A Lenglet $^{2}$, W Van Bortel ${ }^{2}$, I Terzaki ${ }^{1}$, M Tseroni $^{1}$, M Detsis ${ }^{1}$, E Papanikolaou ${ }^{1}$,

A Balaska ${ }^{1}$, S Gewehr $^{3}$, G Dougas ${ }^{1}$, T Sideroglou ${ }^{1}$, A Economopoulou ${ }^{1}$, N Vakalis ${ }^{4}$, S Tsiodras ${ }^{1}$, S Bonovas ${ }^{1}$, J Kremastinou ${ }^{1}$

1. Hellenic Centre for Disease Control and Prevention, Athens, Greece

2. European Centre for Disease Prevention and Control (ECDC), Stockholm, Sweden

3. Ecodevelopment S.A., Thessaloniki, Greece

4. National School of Public Health, Athens, Greece

Citation style for this article:

Danis K, Baka A, Lenglet A, Van Bortel W, Terzaki I, Tseroni M, Detsis M, Papanikolaou E, Balaska A, Gewehr S, Dougas G, Sideroglou T, Economopoulou A, Vakalis N, Tsiodras S, Bonovas S, Kremastinou J. Autochthonous Plasmodium vivax malaria in Greece, 2011.

Euro Surveill. 2011;16(42):pii=19993. Available online: http://www.eurosurveillance.org/ViewArticle.aspx?Articleld=19993

Article published on 20 October 2011

Between May and September 2011, twenty cases of Plasmodium vivax infection were reported in Greek citizens without reported travel history. The vast majority of those cases were confined to a delimited agricultural area of Evrotas, Lakonia. Conditions favouring locally acquired transmission of malaria, including the presence of competent vectors and migrants from endemic countries exist in Greece, underscoring the need for the development of an integrated preparedness and response plan for malaria prevention.

In 2011, 20 malaria cases without reported travel history to endemic countries have been notified as of 27 September from Evrotas, Lakonia and other geographical areas in Greece. We conducted an investigation to describe the geographical and temporal distribution of those cases, determine the affected area(s) and identify the potential source of infection, in order to better understand the transmission dynamics and implement targeted control measures.

Malaria was officially eliminated from Greece in 1974, following an intense national malaria eradication programme that was implemented between 1946 and 1960 [1]. Between 1975 and 2005 approximately 50 cases of malaria were reported annually, the vast majority of whom were imported cases from countries endemic for malaria. However, sporadic cases of mosquito-transmitted malaria that could have been acquired locally were reported in 1991, 1999 and 2000 [2]. Between 2005 and 2009, 171 cases of malaria were reported in Greece with a mean number of 34 cases per year [3]. Of those, $98 \%$ were in people that likely acquired the infection in endemic countries and $78 \%$ of all cases were in migrants from those countries.

Between early August and October 2009, a cluster of eight malaria cases was notified to the Hellenic Centre for Disease Control and Prevention (HCDCP) from the Evrotas area of Lakonia district, which is located in the Peloponnese in southern Greece. The first two cases were in migrant workers from Pakistan and Afghanistan who reportedly arrived in Greece during the summer of 2009 and who were working in the agricultural holdings in this particular area. Four of the remaining six cases belonged to the local Roma community and the other two were Greek citizens residing in the area. None of those six cases reported travel history to a malaria endemic country. In 2010, another malaria case was notified from the same area in Evrotas, who also belonged to the local Roma community. Additionally, two Roma children with malaria were notified in Viotia with disease onset on 25 and 30 August 2010 and an unclear travel history.

\section{Surveillance of malaria in Greece}

As part of the mandatory notification system, physicians in Greece are asked to notify HCDCP of all cases of laboratory-confirmed malaria infection. Enhanced surveillance is implemented in areas where domestic transmission is suspected (i.e. where no clear recent travel history to a malaria-endemic country can be established), by tracing the reported cases, visiting their homes and if possible conducting face-toface interviews. When this is not possible, telephone interviews are conducted. Translators are used where appropriate. The case investigation form for enhanced surveillance gathers information on: detailed travel history, potential modes of transmission, clinical manifestations and treatment, previous malaria clinical episodes, possible onward transmission and household characteristics. In addition, active surveillance is implemented by maintaining weekly communication with local laboratories to enquire about recent diagnosed cases of malaria. Residents in the neighbourhoods surrounding the homes of suspected locally-acquired cases are asked to report febrile illnesses to the local public health office and to seek healthcare promptly.

\section{Laboratory investigation}

Light microscopic examination of Giemsa stained thick and thin blood smears is used to identify malaria 
parasites in local laboratories. Blood smears are routinely analysed when general blood count tests identify anaemia, thrombocytopenia or other abnormal findings. All blood specimens positive for malaria and a number of negative ones are forwarded to the National Malaria Reference Laboratory (MRL) at the National School of Public Health in Athens to be validated with both microscopy and polymerase chain reaction (PCR). Rapid diagnostic antigen tests are not routinely used. Twenty per cent of positive samples are being genotyped at present.

\section{Entomological investigation}

Following the 2010 large outbreak of West Nile Virus infection in Greece [4], a study on vector distribution and mapping of risk areas was carried out. The adult mosquito population is monitored using $\mathrm{CO}_{2}$ or $\mathrm{CO}_{2}-$ light traps at permanent sampling stations that are collected every 14 days. Several additional traps were used at locations of suspected malaria transmission in order to detect Anopheles mosquitoes. Collected specimens were counted and morphologically identified.

\section{Situation in 2011}

\section{Epidemiological and clinical findings}

Up to 27 September 2011, the HCDCP has received reports of 20 cases of $P$. vivax infection in Greek citizens who did not report travel to an endemic country. The majority of those cases $(n=14)$ reside in the agricultural area of Evrotas, Lakonia district (Table, Figure 1). The remaining six Greek cases were reported from four other prefectures, namely Eastern Attiki $(n=2)$, Evia $(n=2)$, Viotia $(n=1)$, and Larissa $(n=1)$. From the area of Evrotas were further reported 16 cases of $P$. vivax infection in migrant workers from endemic countries (mainly from Pakistan) for whom no clear malaria importation status can be determined. In addition, two Romanian workers who had been working and living in the area of Evrotas developed symptoms in July 2011 and were diagnosed with $P$. vivax infection upon their return to Romania [5]. These two cases are not included in further analysis because not all the epidemiological information is available. All 36 cases have been confirmed as $P$. vivax infections, by both microscopy and PCR at

\section{TABLE}

Reported Plasmodium vivax infections by district of residence, Greece, May-September $2011(n=36)$

\begin{tabular}{|l|c|}
\hline District (region) & Number of cases \\
\hline Lakonia (Peloponnese) & $30^{\mathrm{a}}$ \\
\hline Eastern Attiki (Attiki) & 2 \\
\hline Evoia (Sterea Ellada) & 2 \\
\hline Viotia (Sterea Ellada) & 1 \\
\hline Larissa (Thessalia) & 1 \\
\hline Total & $36^{\mathrm{a}}$ \\
\hline
\end{tabular}

a This figure includes 16 cases in migrant workers from endemic countries residing in Evrotas area, Lakonia. The remaining cases are in Greek citizens without reported travel history to a malariaendemic country. the MRL. None of the cases had a history of recent blood transfusion or tissue/organ transplantation.

The first case from Evrotas reported disease onset on 23 May 2011 (Figure 2). An increasing number of cases residing in Evrotas area was observed during September (weeks 35-37). At the time of publication of this report, the outbreak is still ongoing.

The age distribution of the 36 reported cases ranged from 1.5-79 years (median: 36 years). The median age of migrant cases (24 years; range 15-55 years) was significantly lower ( $p<0.001)$ than of Greek cases ( 47 years; range 1.5-79 years), possibly reflecting the different age distributions of the two population groups. Seven of the Greek cases were female. As the majority of the migrant worker community is male, women with $P$. vivax infection were not reported among migrants.

Fever was reported as the main symptom by all cases, followed by splenomegaly $(n=14)$ and anaemia $(n=14)$. Three cases had central nervous symptom manifestations. All cases were hospitalised; one was admitted to an intensive care unit and has recovered fully. To date, there has been one fatality in an elderly male case from Evrotas area who had several underlying medical conditions, including cardiac insufficiency, arrhythmias and chronic obstructive pulmonary disease, and developed acute respiratory distress syndrome. This is the first death associated with $P$. vivax infection in the last three years in Greece. All other cases have fully recovered.

Almost all cases but three who were prescribed mefloquine and primaquine, received the current treatment regimen for uncomplicated $P$. vivax infection according to the national guidelines [6], which is three-day chloroquine treatment followed by 14 -day primaquine treatment. Some cases in Lakonia received the alternative weekly primaquine outpatient regimen (higher dose than the daily regimen) for eight weeks, to achieve a higher compliance rate. Only one case among the reported 36 cases had glucose-6-phosphate dehydrogenase deficiency and did not receive primaquine.

When comparing the date of onset of symptoms to the date of hospitalisation (which is a proxy for receipt of anti-malaria treatment in Greece), the time period for all cases ranged between 0 and 27 days (median: 4 days). The median delay between symptom onset and treatment was shorter in the group of migrant workers (3 days; range 0-19 days) compared to Greek patients (4 days; range 2-27 days). However, this difference was not statistically significant $(p=0.12)$.

\section{Entomological findings}

Fifteen Anopheles species occur in Greece, of which five are considered as potential malaria vectors, namely An. claviger, An. hyrcanus, An. maculipennis, An. sacharovi and An. superpictus [7-9]. In the Evrotas area, Anopheles larvae were found in rivers, reed beds, the 
Vivari lake and draining channels, but at very low densities. From 1 June to 15 September, 23 adult Anopheles specimens were collected from two sampling stations in the area, most of them An. sacharovi $(n=21)$. Two specimens which were determined as $A n$. plumbeus need further confirmation as they were not intact.

In the wetland area of Schinias national park in, Eastern Attiki, 19 mosquito species were identified, with An. claviger being the dominant Anopheles species in the area [9]. Other Anopheles species that were collected in that area included: An. algeriensis, An. maculipennis s.s., An. pseudopictus and An. sacharovi. In the remaining affected areas in Greece, Anopheles species were identified, but their reported densities were often low. The most commonly identified species there were An. sacharovi and An. claviger.

\section{Discussion}

As of 27 September, 20 malaria cases were reported in Greece, affecting Greek citizens who did not have any reported history of travel to a country endemic for malaria. The vast majority of those cases were confined to a delimited geographical area in Evrotas, Lakonia, where a small number of malaria cases had already occurred in the previous two years. All other areas that reported cases were previously unaffected. In addition, 16 cases in migrant farm workers with unclear malaria importation status were notified in Evrotas. As none of these workers were documented, it is difficult to ascertain when they first arrived in Greece, where they travelled and worked and how long they had been residing in the area. Therefore, based on their self-reported travel, medical history and possibility of relapses, it cannot be determined conclusively whether they were non-imported cases.

\section{FIGURE 1}

Place of residence of reported malaria cases, Greece, May-September $2011(n=36)$

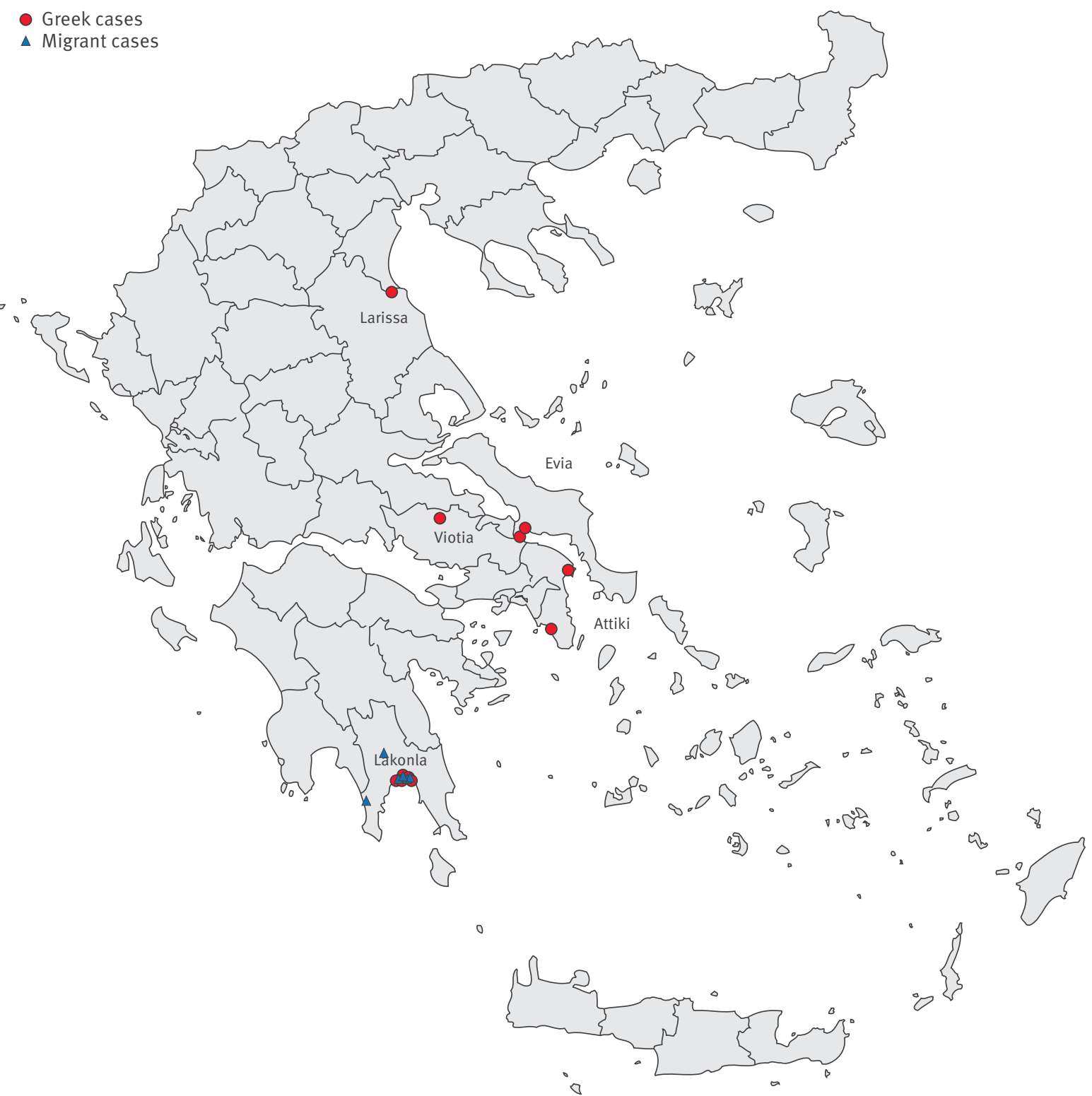


The affected area in Lakonia district is a plain agricultural area of about $20 \mathrm{~km}^{2}$ in the delta of the Evrotas river. It was one of the historical hot spots of malaria transmission before elimination of the disease in Greece [10]. The area is characterised by freshwater springs, a complex network of $130 \mathrm{~km}$ of irrigation and drainage channels, the Evrotas river delta, the brackish Vivari lake, which seasonally dries out, and coastal wetlands. All other affected sites are located in agricultural areas, often closely associated with river deltas or wetland areas, providing favourable conditions for the presence and reproduction of potential malaria mosquito vectors. None of those areas are tourist destinations.

The affected area of Evrotas has a population of 4,485 and a large community of migrant farm workers (estimated between 2,000-4,000 depending on the period of the year), most of whom not registered [11]. Approximately $80 \%$ of all migrant workers in the area come from Pakistan, around $15 \%$ from Romania and the remaining from Morocco. The other affected areas have high numbers of migrant agricultural workers from malaria-endemic countries, predominantly from the Indian subcontinent.

Following the reports of malaria in Greece, the following control measures were introduced: Guidelines for the recognition, management and diagnosis of malaria were provided to healthcare professionals to improve their awareness of the disease. Interviewed patients were informed that persons in their close environment presenting with fever should get diagnosed as soon as possible. Support was provided to strengthen the laboratory capacity of local health centres in the affected areas to diagnose malaria. Surveillance of mosquitoes was enhanced in the affected areas. Guidance for blood and blood product safety according to European Union directives was implemented, including deferral from blood donation for a period of six months of persons residing or working in the affected areas within a radius of $10 \mathrm{~km}$. Communication and health promotion activities were strengthened encouraging personal protection against mosquito bites in the general

\section{FIGURE 2}

Reported cases of malaria by week of symptom onset and region of residence, Greece, May-September $2011 \quad(n=36)$

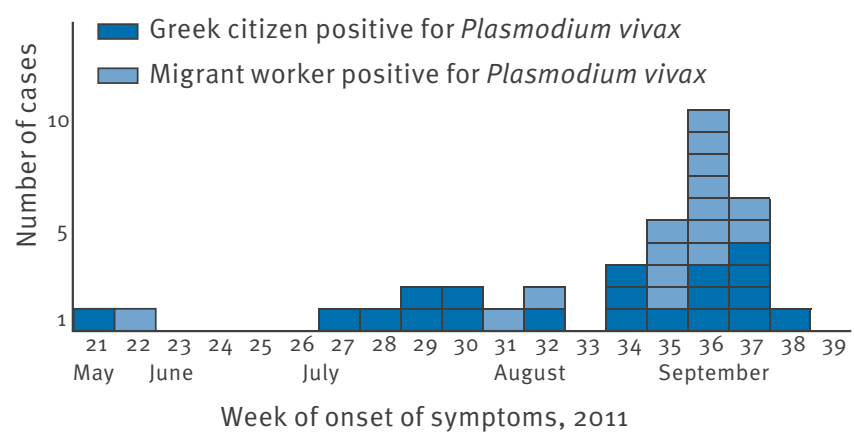

population. Intensified vector control activities were implemented using larviciding in breeding sites, ultralow volume spraying in the affected villages and outdoor residual spraying in a zone of 50 meters around the houses of the cases, including backyards, neighbouring stockyards and other installations favourable for the resting of Anopheles adults. Furthermore, all households in the area have been visited fortnightly since 30 September to detect people with fever and to ensure early detection and prompt treatment of all malaria cases. During those visits, multidisciplinary health teams screened blood smears from all persons with fever of $37.5{ }^{\circ} \mathrm{C}$ or higher, current or reported during the previous 15 days.

Since the malaria eradication in 1974 in Greece, sporadic cases of probable local mosquito-borne transmission have occurred. Because of its climate, proximity of human and mosquito populations, and the increased number of migrants from malaria-endemic countries, Greece and possibly other Mediterranean countries might be vulnerable to the re-establishment of endemic malaria $[12,13]$. However, provided that current healthcare, mosquito control and public health infrastructures remain intact in Greece, the re-establishment of endemic areas for malaria remains unlikely. Nevertheless, conditions may exist for small clusters of locally acquired mosquito-borne transmission to occur sporadically. The development of an integrated preparedness and response plan for malaria that covers all aspects from surveillance, clinical management, laboratory diagnosis, entomological surveillance, vector control and communication is necessary to prevent transmission and control the disease on the long term. Such a plan should not only address the most affected area of Evrotas, Lakonia, but also other parts of Greece where ecological parameters are favourable for malaria transmission.

\section{Acknowledgments}

We would like to thank all hospital physicians and local public health authorities who contributed to the surveillance of malaria infections in Greece; the internists and microbiologists at the General Hospital of Sparti; the personnel of the National Malaria Reference Laboratory for technical support. We would like to thank Katrin Leitmeyer, Lara Payne and Herve Zeller at the European Centre for Disease Prevention and Control for their continued support during this event.

\section{References}

1. World Health Organization (WHO). Malaria elimination: a field manual for low and moderate endemic countries. Geneva: WHO; 2007. Available from: http://whqlibdoc.who.int/ publications/2007/9789241596084_eng.pdf

2. Kampen H, Proft J, Etti S, Maltezos E, Pagonaki M, Maier WA, el al. Individual cases of autochthonous malaria in Evros Province, northern Greece: entomological aspects. Parasitol Res. 2003;89(4):252-8.

3. Hellenic Centre for Disease Control and Prevention (HCDCP), Department of Epidemiological Surveillance and Intervention. Epidemiological data for malaria in Greece, 2005 to 2009. Athens: HCDPC. [Accessed.23 Sept 2011]. Available from: http://www.keelpno.gr/images/stories/keelpno/malaria/2011/ malaria_2009_eng.pdf 
4. Danis K, Papa A, Theocharopoulos G, Dougas G, Athanasiou M, Detsis $M$, et al. Outbreak of West Nile virus infection in Greece, 2010. Emerg Infect Dis. 2011;17(10):1868-72.

5. Florescu SA, Popescu CP, Calistru P, Ceausu E, Nica M,

Toderan A, et al. Plasmodium vivax malaria in a Romanian traveller returning from Greece, August 2011. Euro Surveill. 2011;16(35):pii=19954. Available from: http://www.

eurosurveillance.org/ViewArticle.aspx?Articleld=19954

6. Hellenic Centre for Disease Control and Prevention (HCDCP).

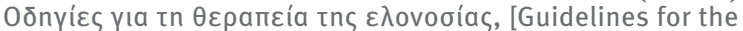
treatment of malaria]. [Accessed 23 Oct 2011]. Available from: http://www.keelpno.gr/images/stories/keelpno/malaria/2011/ odigies_therapia_elonosias_10102011.pdf

7. Darsie RF Jr, Samanidou-Voyadjoglou A. Keys for the identification of the mosquitoes of Greece. J Am Mosq Control Assoc. 1997;13(3):247-54.

8. Samanidou-Voyadjoglou A, Darsie RF Jr. An annotated checklist and bibliography of the mosquitoes of Greece (Diptera: Culicidae). Mosq Syst. 1993;25(3):177-85.

9. Patsoula E, Samanidou-Voyadjoglou A, Spanakos G, Kremastinou J, Nasioulas G, Vakalis NC. Molecular characterization of the Anopheles maculipennis complex during surveillance for the 2004 Olympic Games in Athens. Med Vet Entomol. 2007;21(1):36-43.

10. Vine MJ. The anti-malaria campaign in Greece (1946). Bull World Health Organ. 1948;1(1):197-204.

11. Hellenic Statistical Authority (EL. STAT.). Mid-year estimated population by 5-year age groups level NUTS III (NOMOS). Population by usual residence. Pireus: EL. STAT. [Accessed 26 Sept 2011]. Available from: http://www.statistics.gr/ portal/page/portal/ver-1/ESYE/BUCKET/A1602/Other/ A1602_SPO18_TS_AN_00_1991_00_2007_08_F_EN.pdf

12. Sabatinelli G, Ejov M, Joergensen P. Malaria in the WHO European Region (1971-1999). Euro Surveill. 2001;6(4):pii=213. Available from: http://www. eurosurveillance.org/ViewArticle.aspx?Articleld=213

13. Santa-Olalla Peralta $P$, Vazquez-Torres MC, Latorre-Fandós E, Mairal-Claver P, Cortina-Solano P, Puy-Azón A, et al. First autochthonous malaria case due to Plasmodium vivax since eradication, Spain, October 2010. Euro Surveill. 2010;15(41): pii=19684. Available from: http://www. eurosurveillance.org/ViewArticle.aspx?Articleld=19684 